\title{
Limites e alcances da propaganda do Estado Novo para mobilização nacional durante a Segunda Guerra Mundial
}

\author{
Limits and scope of Estado Novo advertisement for national \\ mobilization during World War II
}

\section{Patrícia Costa de Alcântara *}

Resumo: $O$ artigo aponta alguns limites e alcances da propaganda de mobilização nacional, durante a Segunda Guerra Mundial, como possibilidade de reflexão sobre as relações estabelecidas entre Estado e classe trabalhadora e também sobre as possíveis causas do enfraquecimento da ditadura do Estado Novo, a partir da análise dos processos trabalhistas impetrados nas Juntas de Conciliação e Julgamento de Belo Horizonte, entre 1939 e 1945, e dos textos publicados pela Revista do Trabalho e pelo jornal Estado de Minas, no mesmo período.

Palavras-chave: Segunda Guerra Mundial; Justiça do Trabalho; Trabalhadores.

\begin{abstract}
The paper shows some limits and scope of the national mobilization propaganda, during World War II, as a possibility for reflection about the relations established between state and working class and also about the possible causes of the weakening of the Estado Novo dictatorship, from the analysis of the labor lawsuits filed at the Conciliation and Judgment Boards of Belo Horizonte between 1939 and 1945 and of the texts published by Revista do Trabalho and Estado de Minas newspaper, during the same period.
\end{abstract}

Keywords: World War II; Labor Justice; Workers.

\section{Introdução}

A mobilização nacional fez parte do "esforço de guerra" empreendido a partir do momento em que o Brasil entrou oficialmente em confronto com a Alemanha e a Itália, em agosto de 1942. Tal esforço incluiu o estabelecimento de racionamentos, leis, decretos e normas, criados em decorrência da guerra, assim como a elaboração de diversos argumentos discursivos utilizados pelo governo para mobilizar civis, militares, trabalhadores e empresários para um esforço coletivo em busca da estabilidade político-econômica brasileira, durante o período de beligerância.

A publicidade e as transformações ocasionadas pela participação do Brasil na Segunda Guerra Mundial repercutiram nos conflitos trabalhistas tramitados nas 
Juntas de Conciliação e Julgamento (JCJ), ${ }^{1}$ fato capaz de revelar fragmentos importantes da complexidade existente nas relações e comunicações estabelecidas entre Estado e sociedade. Neste caso em especial, entre o governo e os atores que compunham os mundos do trabalho, num momento em que a industrialização, o nacionalismo e a regulação das relações laborais eram características marcantes do projeto de um Estado autoritário.

Boa parte do conjunto jurídico sobre o trabalho sistematizado durante o governo de Getúlio Vargas tem origem anterior à sua chegada ao posto de chefe de Estado. Durante a Primeira República as relações de trabalho não estavam isentas da interferência legal governamental. As chamadas "leis sociais" englobavam as leis trabalhistas, previdenciárias e de regulação das formas de associação dos trabalhadores - fossem eles operários ou ex-escravizados. Antes da chamada "Revolução de 1930", diversas foram as experiências dos agentes históricos em busca da regulação pública da vida social ou, em outras palavras, de luta por direitos. ${ }^{2}$

No entanto, o Estado ainda relegava a questão social "à polícia ou às instituições filantrópicas, ambas encarregadas de administrar ou prevenir conflitos sociais. [...] O Estado não chamava para si a responsabilidade pela resolução da questão social"3 e nem a regulamentação pública das relações de trabalho possuía a centralidade que viria a ter na agenda do governo no pós-1930.

Sob a égide de Getúlio Vargas, o país investiu no desenvolvimento econômico centrado na indústria e no mercado interno. Assumindo-se como o maior responsável pelo incentivo e pela organização desse processo, o governo estruturou mecanismos de intermediação de interesses entre o Estado e os agentes econômicos. Construiu também um ordenamento jurídico que, ao mesmo tempo em que ampliava os direitos individuais dos trabalhadores, impunha uma estrutura sindical corporativista que estabelecia limites às negociações diretas entre trabalhadores e patrões ${ }^{4}$. Os dissídios trabalhistas até então resolvidos no espaço privado da produção passariam a ser regulados por parâmetros definidos pelo poder público. ${ }^{5}$

\footnotetext{
As Juntas de Conciliação e Julgamento eram os órgãos responsáveis pela solução das causas trabalhistas individuais e foram criadas pelo Decreto 22.132, de 25 de novembro de 1932. Em 1941, tornaram-se os tribunais de primeira instância da Justiça do Trabalho, composta também pelos tribunais de segunda, os Conselhos Regionais do Trabalho e de terceira instância, o Conselho Nacional do Trabalho.

2 VISCARDI, Cláudia Maria Ribeiro. Trabalho, previdência e associativismo: as leis sociais na Primeira República. In: DELGADO, I. G.; LOBO, V. M.; VISCARDI, C. M. (org.). Trabalho, proteção e direitos: o Brasil para além da Era Vargas. Juiz de Fora: Ed. UFJF, 2010.

3 Ibidem, p. 58.

4 GOMES, Ângela Maria de Castro. Ideologia e trabalho no Estado Novo. In: PANDOLFI, Dulce (org.). Repensando o Estado Novo. Rio de Janeiro: Ed. FGV, 1999.

5 SILVA, Fernando Teixeira. Trabalhadores no Tribunal: conflitos e Justiça do Trabalho em São Paulo no contexto do Golpe de 1964. São Paulo: Allameda, 2016.
} 
Nesse sentido, foram elaborados órgãos específicos para arbitrar conflitos entre patrões e operários. Em 1932, foram criadas as Juntas de Conciliação e Julgamento, órgãos responsáveis pela solução das causas individuais, ${ }^{6}$ e as Comissões Mistas de Conciliação, órgãos conciliadores em caso de ações trabalhistas coletivas. ${ }^{7}$ Mais tarde, esses primeiros órgãos passaram a integrar a Justiça do Trabalho (JT), que foi organizada pelo governo em maio de $1939^{8} \mathrm{e}$ regulamentada em dezembro de $1940 .{ }^{9}$ No dia $1^{\circ}$ de maio de 1941 , esse ramo específico do Direito foi declarado oficialmente estabelecido em ato público realizado por Getúlio Vargas no estádio de futebol Vasco da Gama. ${ }^{10}$

Em âmbito internacional, todos esses acontecimentos foram concomitantes ao amadurecimento do posicionamento brasileiro ante a Segunda Guerra Mundial e a sua subsequente adesão ao grupo dos Aliados. O planejamento, a organização e a instalação da Justiça do Trabalho foram simultâneos ao desenrolar da guerra. Brasil posicionava-se frente ao conflito e suas consequências sociais, econômicas e políticas enquanto esse ramo específico do Direito era desenvolvido e implementado. O contexto beligerante ocasionou transformações no campo dos direitos sociais e nas relações de trabalho em escala global, e os acontecimentos ocorridos no espaço nacional não estavam desvinculados desses processos mais amplos, como trataremos brevemente adiante.

Os brasileiros lidaram com duas novidades que alteraram significativamente as suas atividades diárias: uma justiça gratuita criada para arbitrar as relações entre patrões e empregados e uma guerra mundial para a qual foram convocados a participar como reservistas, como convocados a constituir a Força Expedicionária

$6 \quad$ BRASIL. Decreto n. 22.132, de 25 de novembro de 1932. Institui Juntas de Conciliação e Julgamento e regulamenta as suas funções. Coleção das Leis da República. Disponível em: https://www2.camara.leg.br/atividade-legislativa/legislacao/republica. Acesso em: 22 jul. 2019.

7 BRASIL. Decreto n. 21.396, de 12 de maio de 1932. Institui Comissões Mistas de Conciliação e dá outras providências. Coleção das Leis República. Disponível em: https://www2.camara.leg.br/atividade-legislativa/legislacao/republica. Acesso em: 22 jul. 2019.

8 BRASIL. Decreto-lei n. 1.237, de 2 de maio de 1939. Organiza a Justiça do Trabalho. Coleção das Leis República. Disponível em: https://www2.camara.leg.br/atividadelegislativa/legislacao/republica. Acesso em: 22 jul. 2019.

9 BRASIL. Decreto-lei n. 6.596, de 12 de dezembro de 1940. Aprova o regulamento da Justiça do Trabalho. Coleção das Leis República. Disponível em: https://www2.camara.leg.br/atividadelegislativa/legislacao/republica. Acesso em: 22 jul. 2019.

10 BILHÃO, Isabel. Trabalhadores do Brasil!: as comemorações do primeiro de maio em tempos de Estado Novo varguista. Revista Brasileira de História, São Paulo, v. 31, n. 62, p. 71-92, 2011. Aproveito a nota para acrescentar que é possível estender as origens da Justiça do Trabalho à criação do Ministério do Trabalho em 1930, ou ainda mais, remontando aos tribunais rurais de São Paulo. Para uma análise mais alargada sobre o assunto, ver: GOMES, Ângela Maria de Castro; SILVA, Fernando Teixeira da. A Justiça do Trabalho e sua história: os direitos dos trabalhadores no Brasil. Campinas: Editora da Unicamp, 2013. De todo modo, foi a partir de 1932 que a máquina de regulação trabalhista adquiriu de fato maior complexidade e abrangência. 
Brasileira, a Força Aérea Brasileira e a Marinha, ou como "soldados da produção", ${ }^{11}$ impelidos a participar do conflito a partir das trincheiras fabris. Os eventos sobre a Segunda Guerra Mundial eram divulgados pelos veículos de comunicação do país ao mesmo tempo em que também eram noticiadas as novas legislações sociais e trabalhistas.

\section{Trabalho e Guerra na Mídia}

Trabalho e guerra se aproximaram progressivamente ao longo do conflito, principalmente após a entrada oficial do Brasil no combate. Notícias sobre a guerra e a Justiça do Trabalho eram divulgadas cotidianamente pelo governo e os temas passaram a apresentar caráter de complementaridade no discurso de propaganda do Estado Novo para mobilização nacional durante a Segunda Guerra Mundial.

Para que possamos compreender a evolução e o imbricamento desses temas, é preciso considerar que o estabelecimento de novos padrões de relações de trabalho que possibilitaram o fortalecimento do populismo varguista está relacionado ao impacto do esforço de guerra nas diversas regiões do planeta e a consequente alteração da geopolítica mundial. ${ }^{12}$

A atuação da União das Repúblicas Socialistas Soviéticas (URSS) contra a Alemanha nazista; as tensões entre capitalismo e comunismo; o repúdio a governos autoritários como os nazifascistas e os apelos democráticos são algumas das mudanças que acarretaram a necessidade de uma maior proximidade entre Estado e classe trabalhadora para que a implementação dos direitos sociais ocorresse dentro dos limites do capitalismo.

Em âmbito nacional, o contexto da guerra foi propício ao projeto desenvolvimentista de Vargas, que usou os sentimentos nacionalistas para angariar esforços dos trabalhadores. O presidente incentivou projetos; desenvolveu e apoiou campanhas de mobilização populares e/ou empresariais; promoveu atos em comemoração às vitórias dos Aliados. Durante o conflito foi possível promulgar leis que afetavam a Justiça do Trabalho e a Consolidação das Leis Trabalhistas sem que esses pilares de propaganda do governo perdessem credibilidade.

11 Conclamados pelo governo a colaborar com o esforço de guerra através do trabalho nas fábricas, os trabalhadores civis eram constantemente referidos como "soldados operários" ou "soldados da produção".

12 FORTES, Alexandre. Do reformismo tecnocrático ao nacionalismo de massas: A Segunda Guerra Mundial e a emergência do trabalhismo brasileiro. In: FERRERAS, Norberto. (org.). A questão nacional e as tradições nacional-estatistas na América Latina e na África. Rio de Janeiro: Ed. FGV, 2015. 
O envolvimento do país no conflito permitiu que o governo empreendesse um nacionalismo popular que investiu na mobilização estatal das massas, dos partidos e outros movimentos sociais para dar sustentação política ao regime. A partir da mobilização, Vargas pôde se situar na política e economia internacionais, ao mesmo tempo em que, em âmbito doméstico, pôde integrar, num mesmo propósito de unidade nacional, grupos diversos que possuíam interesses distintos. Sobre esse aspecto, é importante lembrar que a circunstância da guerra tornou possível que, pela primeira vez, comunistas apoiassem o presidente. ${ }^{13}$

Embora, de uma forma geral, as manifestações de massa do período contassem com a anuência do governo, grupos com ambições políticas diversas disputavam a instrumentalização dos ânimos exaltados imbuídos de nacionalismo. Não por acaso, o discurso de "união nacional", difundido inclusive por lideranças comunistas, ${ }^{14}$ precisou ser acompanhado da intensificação do apelo de "paz entre as classes" propagandeado sobretudo pelo Estado Novo.

Coação, vigilância e propaganda, aliados à ideologia trabalhista e ao esforço de guerra, causaram impacto significativo sobre a classe trabalhadora. Esse impacto deu-se tanto em níveis práticos, pela carestia de determinados víveres e pela ordenação das relações de trabalho, quanto em níveis ideológicos, por meio de um trabalho ativo do Estado e da burguesia em difundir a ideologia de uma "batalha da produção" capaz de construir entre os trabalhadores a imagem de um "soldadooperário" que os fizesse acreditar que o melhor papel que poderiam desempenhar no conflito seria a transformação do nacionalismo em disciplina fabril. ${ }^{15}$

Acentuada a partir da ditadura do Estado Novo, a repressão estatal conciliou violência e um discurso político que apresentava a paz social como essencial ao desenvolvimento do país e era marcado por forte apelo anticomunista. Assim, para Marcelo Badaró Mattos, são várias as heranças daquele período,

3 CARONE, Edgard. O PCB (1943-1964). São Paulo: DIFEL, 1982. v. 2.

14 CARONE, op. cit. Sem página porque é citação indireta. Com a instalação da ditadura do Estado Novo, a atuação do Partido Comunista do Brasil sofre um forte abalo. No entanto, a ofensiva nazista sobre o território da URSS significou um catalizador para reorganização comunista no país. Naquela conjuntura, prevaleceu o entendimento de que a "união nacional" em torno de Getúlio era fundamental para o enfrentamento do nazifascismo, já que, na perspectiva comunista, ao declarar guerra à Alemanha nazista, o Brasil teria se tornado aliado da URSS, ainda que momentaneamente.

15 PUREZA, Fernando Cauduro. Economia de guerra, batalha da produção e soldados operários: O impacto da Segunda Guerra Mundial na vida dos trabalhadores de Porto Alegre (1942-1945). 2009. Dissertação (Mestrado em História) - Universidade Federal do Rio Grande do Sul, Porto Alegre, 2009. 
mas a mais importante entre elas foi, sem dúvida, a proposta, difundida nos discursos dos dirigentes da época, de convivência harmônica entre trabalhadores e empresários, arbitrada por um Estado que seria, ainda segundo aqueles discursos, ao mesmo tempo regulador e protetor, apresentando-se como inventor da legislação social. ${ }^{16}$

A preocupação do governo Vargas com publicidade e propaganda de Estado remonta a um período anterior, mas foi também durante a Segunda Guerra Mundial que se estabeleceram os contornos do Departamento de Imprensa e Propaganda (DIP),${ }^{17}$ um amadurecimento de outras investidas anteriores e o início de, "[...] possivelmente, uma das mais bem sucedidas campanhas de propaganda política de nosso país". ${ }^{18}$

O DIP deveria dirigir e supervisionar as informações sobre o Regime, criar e difundir uma imagem positiva do Estado Novo e da figura de Getúlio Vargas, divulgar seus feitos e censurar a veiculação de manifestações contrárias ao governo. Tudo isso era feito por meio do controle dos meios de informação da época, como o rádio, o cinema e a imprensa, além de festividades, concursos, cartazes, artigos e livros. Incumbido de sistematizar e divulgar suas mensagens para entidades públicas e privadas, o órgão contava ainda com ramificações estaduais que possuíam as mesmas funções, os Departamentos Estaduais de Imprensa e Propaganda (DEIP). ${ }^{19}$

Em dimensões nacionais, o rádio, que era o principal meio de comunicação da época, tornou-se o principal veículo de difusão das propagandas do Estado Novo e dos temas trabalho e guerra. Tendo como principal público ouvinte os "trabalhadores do Brasil", Alexandre Marcondes Filho, ministro do Trabalho, Indústria e Comércio de 1942 a 1945, apresentava-se semanalmente pela Rádio Nacional no programa de rádio Hora do Brasil, produzido pelo DIP. Apesar do conteúdo do programa constituirse basicamente de notícias e explanações sobre a legislação social e trabalhista, eram abordados temas da conjuntura política nacional e internacional. ${ }^{20}$

\footnotetext{
16 MATTOS, Marcelo Badaró. Trabalhadores e sindicatos no Brasil. São Paulo: Expressão Popular, 2009. p. 61.

17 Criado pelo Decreto-lei 1.915, de 27 de dezembro de 1939, o DIP foi extinto pelo Decreto-lei 7.582 em 25 de maio de 1945. Antecederam ao DIP o Departamento Oficial de Publicidade (1931), o Departamento de Propaganda e Difusão Cultural (DPDC - 1934) e o Departamento Nacional de Propaganda (DNP - 1938).

18 GOMES, Ângela de Castro. A invenção do trabalhismo. São Paulo: Vértice; Editora dos Tribunais, 1988. p. 238.

19 VELLOSO, Mônica Pimenta. Cultura e poder político: Uma configuração do Campo Intelectual. In: OLIVEIRA, L. L.; VELLOSO, M. P.; GOMES, Â. M. de C. (org.). Estado Novo: ideologia e poder. Rio de Janeiro: Zahar, 1982.

20 CAPELATO, Maria Helena. Propaganda política e controle dos meios de comunicação. In: PANDOLFI, Dulce. (org.). Repensando o Estado Novo. Rio de Janeiro: Ed. FGV, 1999.
} 
Notícias sobre a guerra, sobre as adversidades ocasionadas pelo conflito, pronunciamentos de líderes dos países envolvidos e outros temas afins eram constantemente comentados pelo ministro. Ao mesmo tempo, devido ao esforço de guerra, os trabalhadores eram constantemente informados sobre suas novas atribuições e compromissos patrióticos. ${ }^{21}$

No entanto, apesar da importância da radiodifusão, o setor mais eficiente do DIP teria sido a imprensa, particularmente os jornais e revistas que agregavam intelectuais responsáveis pela produção e difusão do discurso do Estado Novo para os demais meios de comunicação. ${ }^{22}$

Vários foram os títulos criados ou encampados com esse propósito ${ }^{23}$ e a maior parte das publicações não pôde ficar alheia aos acontecimentos da Segunda Guerra Mundial. Os casos das revistas Cultura Política e Revista do Trabalho podem ser tomados aqui como exemplares das interfaces entre trabalho, propaganda e guerra.

Editada mensalmente pelo DIP entre 1941 e 1945, o principal objetivo de Cultura Política era a produção e difusão do discurso estado-novista. A publicação era ao mesmo tempo produto e ponto de referência para o corpo burocrático do governo e intelectuais incumbidos de divulgar o regime.

Mesmo antes da ruptura das relações diplomáticas e comerciais com os países do Eixo ou da entrada do Brasil na guerra, a revista possuía textos sobre a política externa brasileira desenvolvida por Getúlio Vargas. No entanto, após o ataque japonês à base estadunidense de Pearl Harbor, publicações sobre a política interna e externa brasileiras relacionadas ao conflito mundial e a questões militares apresentaram um vertiginoso crescimento.

Surgem assim algumas seções dedicadas exclusivamente à questão da guerra, como por exemplo, Política Internacional, O Brasil e a Guerra e O Brasil no Exterior. $^{24} \mathrm{Em}$ agosto de 1943, foi lançado um número extraordinário que apresentava exclusivamente textos relacionados ao envolvimento do Brasil no conflito. ${ }^{25}$

21 GOMES, op. cit.

22 VELLOSO, op. cit.

23 São exemplo jornais como A Manhã e A Noite e revistas como Cultura Política, Ciência Política, Estudos e Conferências, Dos Jornais, Brasil Novo, Planalto e outras.

24 BONET, Fernanda dos Santos. Autoritarismo e nacionalismo: o discurso oficial sobre o envolvimento do Brasil na Segunda Guerra Mundial, através das páginas da revista Cultura Política. 2010. Dissertação (Mestrado em História) - Faculdade de Filosofia e Ciências Humanas, Pontifícia Universidade Católica do Rio Grande do Sul, Porto Alegre, 2010.

25 Luciana Ibarra dos Santos trata especificamente da Edição Comemorativa da Entrada do Brasil na Guerra, publicada pela revista Cultura Política em 1943. SANTOS, Luciana Ibarra dos. Há algo de novo no front: a participação do Brasil na Segunda Guerra Mundial. 2006. Dissertação (Mestrado em História) - Instituto de Ciências Humanas e Sociais, Pontifícia Universidade Católica do Rio Grande do Sul, Porto Alegre, 2006. 
A Revista do Trabalho também era editada mensalmente e permaneceu em circulação entre 1933 e 1965. Inicialmente a publicação se propunha a debater a evolução normativa da legislação social e trabalhista implantada a partir de 1930. Mais tarde, empenhou-se em trazer contribuições para constituição e instalação da Justiça do Trabalho no Brasil e para a Consolidação das Leis do Trabalho. ${ }^{26}$

Possuía seções dedicadas à divulgação de novas leis, jurisprudências e pareceres. Temas pertinentes à experiência de intervenção estatal nas relações econômicas e sociais de diversos países eram debatidos a partir de contribuições voluntárias de juristas iniciantes, mas também de profissionais proeminentes como Segadas Vianna e Arnaldo Süssekind - que mais tarde integraram o corpo de redatores da CLT.

Embora o periódico se apresentasse como iniciativa privada, logo recebeu apoio do Ministério do Trabalho e do Conselho Nacional do Trabalho (CNT) na forma de manchetes, informações e artigos. $O$ afinamento da revista com as diretrizes do governo era orgulhosamente assumido. Não por acaso, em março de 1940, foi publicada na íntegra uma carta assinada pelo procurador geral do CNT, enviada para um dos editores, a fim de parabenizar a "[...] explendida [sic] cooperação que vem prestando ao Ministério do Trabalho, Industria e Comércio [...]" ${ }^{27}$

As edições da revista publicadas entre 1939 e 1945 revelam que os debates sobre legislação trabalhista, Justiça do Trabalho e CLT precisaram incluir as adversidades apresentadas pela guerra. Temas como a regularização dos trabalhadores estrangeiros às leis trabalhistas do país e a aplicação da lei dos $2 / 3^{28}$ estiveram desde o início presentes nos artigos da revista. No entanto, a partir de 1942, trabalhadores italianos, japoneses e alemães passaram a compor um grupo à parte. Designados "súditos do Eixo", ${ }^{29}$ tornaram-se alvo de um debate intenso com vistas à elaboração de uma legislação específica adequada aos tempos de guerra. ${ }^{30}$

26 Esse e os parágrafos seguintes tiveram como fontes as edições da Revista do Trabalho publicadas entre 1939 e 1945, disponíveis para consulta interna na Biblioteca do Tribunal Regional do Trabalho da Terceira Região - Coleção Especial e Livros Raros.

27 Dr. J. Leonel de Resende Alvim à "Revista do Trabalho". Revista do Trabalho, Rio de Janeiro, ano 8, n. 3, p. 5, mar. 1940.

28 O Decreto 19.482, de 12 de dezembro de 1930, visava regular e restringir a entrada de imigrantes no país e já apresentava em seu artigo $3^{\circ}$ a exigência de que dois terços dos empregados das empresas, associações, companhias e firmas comerciais nacionais fossem brasileiros natos. $\mathrm{O}$ Decreto 20.291 , de 12 de agosto de 1931, regulamenta a execução do referido artigo 3ํ․

29 Durante a guerra, foram designados "súditos do Eixo" italianos, japoneses e alemães, assim como seus descendentes. A alcunha era utilizada tanto nos textos oficiais quanto pela população de uma forma geral.

30 O Decreto-lei 4.166, de 11 de março de 1942; o artigo 8o do Decreto-lei 4.637 de 31 de agosto de 1942 e o Decreto-lei 4.638, de mesma data, são apenas alguns exemplos. 
Os direitos de trabalhadores convocados e reservistas, que também já haviam sido apresentados de forma pontual em alguns artigos, passaram a ser amplamente debatidos de dezembro de 1942 até dezembro de $1945 .^{31}$ De maio de 1942 até o julho de 1945, a falta de matéria-prima recebeu atenção especial, embora tenha sido pauta indireta da redação desde dezembro de 1941.

O assunto apresentou ligações com as discussões sobre o que deveria ser caracterizado e aceito como "força maior". Com o aumento do número de demissões justificadas pela "crise do comércio", "falta de matéria-prima" e "racionamentos", todos apresentados como "motivos de força-maior", os artigos sobre a matéria também ganharam fôlego a partir de março de 1942, atingindo o ápice em 1943.

Além do objetivo de instruir diversos setores do corpo burocrático do governo, realizar a propaganda do regime e legitimar suas ações, Cultura Política e Revista do Trabalho apresentam em comum o fato de requalificar o discurso oficial de acordo com a nova conjuntura política, econômica e ideológica trazida pelo conflito global, de forma a realizar a manutenção do governo de Getúlio Vargas no poder.

Embora não tenham sido criadas com esse propósito, essas revistas passaram a apresentar a situação interna e externa do Brasil no conflito, os resultados esperados do pós-guerra e principalmente as ações do Estado no esforço de guerra. A partir desse discurso, o Estado Novo justificava a necessidade de um governo forte, centralizado e nacionalista para a proteção da soberania nacional e, ao mesmo tempo, legitimava a exigência de que a população civil contribuísse com o que estivesse ao seu alcance. Para isso, os periódicos difundiam quais seriam os deveres de empresários e de "soldados da produção" na mobilização econômica, no esforço para a produção e na união nacional. A ajuda não deveria ser, portanto, desordenada. ${ }^{32}$

O ordenamento dos papéis a serem desempenhados denota o caráter autoritário do regime, porém uma das estratégias para afastar a imagem de Getúlio de uma figura ditatorial foi a criação de discursos que aproximavam seus interesses aos interesses populares. Os anseios do Estado Novo e da população se confundem nas propagandas de governo, e a impressão que se tem, não despropositadamente,

31 Foram pautas de discussão, por exemplo, o Decreto-lei 2750, de 6 de novembro de 1940; o Decretolei n. 2.967, de 21 de janeiro de 1941; o Decreto-lei 4902 de 31 de outubro de 1942; o Decreto-lei $n$. 5225, de 1 de fevereiro de 1943; o Decreto-lei 5612 de 24 de Junho de 1943 e o Decreto-lei 5689 de 22 de julho de 1943.

32 Um dos artigos redigidos por Segadas Vianna traz elementos importantes sobre esse empreendimento. O texto justifica a ação do Estado na supressão de determinados direitos trabalhistas e aponta o que se esperava dos trabalhadores durante e depois do confronto. VIANNA, J. de Segadas. A guerra e a situação atual e futura dos trabalhadores. Revista do Trabalho, Rio de Janeiro, ano 10, n. 10, p. 5-7, out. 1942. 
é de que são um só. Nem conflitos de classe, nem os choques de natureza política deveriam ameaçar a unidade brasileira.

Sobre esse aspecto, é interessante perceber que na Revista do Trabalho os discursos sobre a colaboração entre as classes receberam nova conotação a partir de 1942, quando o tema passou a ser associado à noção de "soldados da produção".

Em um primeiro momento, o abandono do conflito de interesses entre patrões e operários era apresentado como essencial para as conquistas em âmbito doméstico:

No Brasil, esse conflito vem sendo previdentemente evitado por uma legislação que coloca capital e trabalho no mesmo nível [sic], como duas forças que, longe de se chocarem, têm de buscar [sic] o seu ponto de harmonia e equilíbrio [sic] em um interesse mais alto e intangível [sic] - o interesse comum, de ordem, de paz, de progresso - com seus alicerces profundos no domínio da economia nacional. ${ }^{33}$

Posteriormente a paz entre as classes passou a ser apresentada como fundamental ao esforço de guerra, um dever patriótico que, aliado à produção para a defesa, seria fundamental para a vitória:

Ora, em tempos de calamidade pública, em tempo de guerra, opera-se uma verdadeira transferência das afinidades. Ou melhor: na realidade amplia-se a idéia [sic] de afinidade, do estreito campo profissional para o campo nacional. E por que? Em virtude da própria lei das afinidades. Surge um interesse maior, que se sobrepõe e absorve o menor. O trabalhador não tem mais ante ele o empreendedor e vice-versa. Ambos têm contra si o inimigo comum. E, portanto, os antagonismos de classe passam para o plano inferior, porque superiores interesses, já comuns a patrões e operários, a defender surgem, que quase sempre repelem, ou, pelo menos, tornam inoportuna outra modalidade de luta (e luta interna, embora, como atualmente entre nós, depois da instituição da Justiça do Trabalho - luta jurídica), desvio de energias, que os prejudicará. Quero dizer: torna-se ativa, em tempo de guerra, a solidariedade nacional. ${ }^{34}$

Houve um alargamento do papel atribuído à "paz entre as classes". Nas palavras de Getúlio Vargas, naquela emergência deveria "[...] cada homem conservar o seu posto sem pensar em sí [sic] próprio, sem pensar na família, sem pensar nos

33 PIMENTA, Joaquim. Comentando.... Revista do Trabalho, Rio de Janeiro, ano 8, n. 2, p. 7-8, fevereiro de 1940.

34 LACERDA, Dorval. A guerra e a legislação brasileira do trabalho. Revista do Trabalho, Rio de Janeiro, ano 11, n. 5, p. 19-21, maio de 1943. 
bens". ${ }^{35}$ Os "homens de trabalho" e "[...] todas as forças vivas da nacionalidade" deveriam estar empenhados "[...] numa luta decisiva para os destinos da Pátria." ${ }^{36}$

Em Belo Horizonte, por via impressa, essas informações eram divulgadas principalmente pelo jornal Estado de Minas. As notícias do conflito e as novidades no campo da legislação trabalhista podiam ser acompanhadas por meio do periódico.

As notícias eram difundidas também em um especial instrumento de divulgação:

Nós tínhamos um placar instalado - nós quando eu digo é o Estado de Minas e o Diário da Tarde - instalado na Praça Sete ${ }^{37}$. Então tínhamos uma pessoa encarregada de duas, três vezes por dia ir à Praça Sete e mudar as manchetes e as notícias principais que chegavam. E ficava às vezes um grupo de populares esperando chegar o nosso encarregado de escrever as notícias no placar, e quando escrevia, ficavam sendo comentadas. Às vezes havia palmas quando a notícia era boa. ${ }^{38}$

Não era incomum nas páginas do jornal notícias semelhantes à de que "[...] sucedem manifestações de apoio e solidariedade de todas as classes da cidade e do Estado à Cruz Vermelha Brasileira, filial de Minas". ${ }^{39}$. Seguindo o modelo das campanhas e dos discursos nacionais, elas frisavam que a união nacional contra um inimigo comum deveria prevalecer sobre as diferenças de classe.

Com a entrada na guerra, os moradores da cidade, assim como todos os demais brasileiros, passaram a ser constantemente arregimentados pelas autoridades políticas para participarem do esforço de guerra como soldados da produção: “[...] trabalhemos nos campos, nas fábricas, nas oficinas, nos arsenais, nas escolas, nas fileiras do nosso glorioso Exercito [sic]; sejamos soldados e sejamos cidadãos; sejamos heróis, mas sejamos humanos". ${ }^{40}$

As notícias sobre a guerra eram estampadas nas primeiras páginas do caderno. Quanto às novidades sobre as regulações do mundo do trabalho:

O Estado de Minas vinha estampando, em suas colunas, o movimento referente à Justiça do Trabalho, Previdencia [sic] Social e vida sindical, em notas esparsas. Dada, porém, a

35 AOS TRABALHADORES do Brasil. Revista do Trabalho, Rio de Janeiro, ano 10, n. 8, p. 5, ago. 1942. Trecho de discurso pronunciado por Getúlio Vargas.

36 O PRESIDENTE Getúlio Vargas aos trabalhadores do Brasil. Revista do Trabalho, ano 11, n. 4, p. 5, abr. 1943. Trecho de discurso pronunciado por Getúlio Vargas por ocasião do 1ํ de maio.

37 No projeto da Comissão Construtora da Capital, a Praça Sete de Setembro, conhecida como Praça Sete, foi concebida para ser o marco do centro da cidade. Atravessada por duas das principais avenidas da cidade, a praça sempre foi a mais movimentada de Belo Horizonte.

38 BERNIS, Ney Octaviani, apud BARROS, José Marcio Pinto de Moura; SANTIAGO, Carla Ferretti. BH nos tempos da Segunda Guerra Mundial. Belo Horizonte: Centro de Referência Áudio Visual, 1995. p. 28.

39 ESTADO DE MINAS, Belo Horizonte, n. 4886, p. 3, 8 set. 1942.

40 A POPULAÇÃO de Belo Horizonte fez da "Pirâmide Metálica" um testemunho do seu patriotismo. Estado de Minas, Belo Horizonte, n. 4886, p. 5, 8 set. 1942. 
amplitude que vão tomando as atividades desses setores da vida nacional, tornou-se aconselhavel [sic] a sistematização desse noticiário, enriquecido, ao mesmo tempo, de matéria doutrinária e jurisprudência. ${ }^{41}$

Assim, a partir de 9 de novembro de 1943, o jornal passou a contar com a seção Justiça Trabalhista e Previdência Social. Se no corpo do jornal as notícias sobre a guerra e a Justiça do Trabalho passaram a ser mais bem organizadas, no cotidiano dos trabalhadores, as experiências continuavam a se misturar. Três dias antes, quando houve uma festividade por ocasião da comemoração da entrada em vigor da CLT, filmes de guerra foram exibidos à rua São Paulo, número 516, seguidos de falas de presidentes de sindicatos de Belo Horizonte. ${ }^{42}$

\section{Paz no discurso, Guerra nos Tribunais}

Em um artigo publicado na Revista do Trabalho em maio de 1943, Dorval Lacerda $^{43}$ disserta sobre as influências que conflitos armados entre nações trazem para os campos do Direito Político, do Direito Social e da Economia. Após discorrer sobre os impactos da Primeira Guerra Mundial no chômage, na transformação dos regimes políticos dos Estados e no desenvolvimento do Direito do Trabalho, o jurista indaga:

Ora, si [sic] tantas e tão importantes consequências surgiram do episódio guerreiro de há vinte anos, bastantes para mudar radicalmente 0 aspecto da civilização - 0 que se não dirá dos resultados que fatalmente advirão do atual conflito, muito mais extenso, em todos os sentidos, que o anterior? ${ }^{44}$

Dentre os possíveis efeitos que a Segunda Guerra Mundial traria ao Direito do Trabalho no Brasil, alguns seriam previsíveis:

Diminuem as possibilidades da existência de conflitos trabalhistas. O direito de litigar, individualmente, é restringido, senão de direito, legalmente, pelo menos de fato, por força do fenômeno que acima apontamos ["a ampliação da ideia de afinidade" em detrimento dos antagonismos de classe], que provoca uma abstenção. ${ }^{45}$

41 JUSTIÇA Trabalhista e Previdência Social. Estado de Minas, Belo Horizonte, n. 5245, p. 5, 9 nov. 1943.

42 CONSOLIDAÇÃO das Leis do Trabalho. Estado de Minas, Belo Horizonte, n. 5243, p. 5, 6 nov. 1943.

43 Dorval Marcenal de Lacerda (Dorval Lacerda), contribuinte da Revista do Trabalho, também foi integrante da comissão redatora da CLT.

44 LACERDA, Dorval. A guerra e a legislação brasileira do trabalho. Revista do Trabalho, Rio de Janeiro, ano 11, n. 5, p. 19-21, maio de 1943.

45 LACERDA, op. cit., p. 20. 
Não foi bem isso o que, na prática, ocorreu. O número de dissídios não diminuiu durante a guerra. ${ }^{46}$ Os processos trabalhistas apresentados às Juntas de Conciliação e Julgamento de Belo Horizonte demonstraram que a guerra mesmo se tornou geradora e catalisadora de tensões e conflitos nas relações de trabalho.

As dificuldades comerciais impostas pelo conflito justificaram demissões pela "crise do comércio". Os racionamentos estabelecidos, tais como o de gasolina e o de energia elétrica, assim como a falta de determinadas matérias-primas como o açúcar, também fundamentaram dispensas ocasionadas pela "situação anormal criada pela guerra". ${ }^{47} \mathrm{O}$ combate ao nazifascismo, que motivou uma crescente xenofobia e a discriminação a japoneses, italianos e alemães, acarretou a demissão de vários trabalhadores caracterizados por seus patrões como "súditos do Eixo". Em represália aos afundamentos dos navios brasileiros em 1942, empregadores dessas nacionalidades tiveram seus estabelecimentos depredados pela massa popular e precisaram demitir seus empregados. O estorno ou pagamento das "Obrigações de

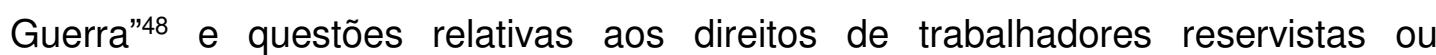
convocados também geraram disputas judiciais.

Todos esses acontecimentos, somados à "legislação de emergência" 49 , fundamentaram causas objetivas ou discursivas para dissídios trabalhistas que foram apresentados às Juntas de Conciliação e Julgamento.

Osias Morais e Irmãos, por exemplo, pediu ao Conselho Regional do Trabalho (CRT) autorização para suspender os serviços porque o principal material empregado na fábrica era o açúcar que, devido ao racionamento, não era obtido em quantidade suficiente à continuação da indústria. O Conselho agendou uma audiência em que deveriam estar presentes um representante da empresa e todos os seus empregados. Naquela sessão, a reclamada insistiu nas suas razões. Em

46 ANUÁRIO Estatístico do Brasil - 1939-1940. Rio de Janeiro: IBGE, 1940. ANUÁRIO Estatístico do Brasil - 1941-1945. Rio de Janeiro: IBGE, 1946.

47 Esse e os próximos parágrafos tiveram como fontes os processos trabalhistas tramitados nas Juntas de Conciliação e Julgamento de Belo Horizonte entre 1939 e 1945, disponíveis para consulta interna no Arquivo Geral do Tribunal Regional do Trabalho da Terceira Região.

48 A contribuição compulsória de todos os trabalhadores para a defesa nacional foi estabelecida pelo Decreto-lei n. 4.789, de 5 de outubro de 1942, que autorizou a emissão de "Obrigações de Guerra". O Decreto-lei n. 5.159, de 31 de dezembro de 1942; o Decreto-lei n. 5.291, de 1ำ de março de 1943 e o Decreto-lei n. 5.505, de 20 de maio de 1943 modificaram e complementaram o inicial. Devido às alterações, as obrigações tornaram-se pautas de processos trabalhistas e foram levadas em consideração para o cálculo final das sentenças e acordos. A subscrição compulsória de Obrigações de Guerra foi suspensa pelo Decreto-lei 9.138 de 5 de abril de 1946.

49 Era chamada "legislação de emergência" ou "legislação de guerra" o conjunto de leis, decretos e normas criados em virtude do conflito mundial e que deveriam vigorar e prevalecer sobre a legislação anterior enquanto perdurasse o estado de guerra. Entre janeiro de 1942 a fevereiro de 1943, pelo menos 78 decretos-lei; 12 portarias ministeriais e uma emenda constitucional foram criados por determinação do Ministério do Trabalho. Fonte: FILHO, Evaristo de Morais. A legislação de guerra de iniciativa do Ministério do Trabalho. Revista do Trabalho, Rio de Janeiro, ano 11, n. 5, p. 21-26, maio 1943. Até 1945 vários outros decretos-lei foram instituídos por iniciativa da pasta. 
resposta, um dos empregados presentes disse que outras fábricas congêneres continuavam suas atividades, atribuindo, "[...] em parte, a falta de açúcar a uma certa imprevidência do proprietário da fábrica, o qual não acumulou o estoque necessário para fazer face à crise". ${ }^{50}$ Meses depois, os empregados reivindicaram à 1 a $\mathrm{JCJ}$ reintegração, salário mínimo, salário em atraso e o pagamento dos dias em que foram suspensos do serviço sem licença legal, além do direito de estabilidade ${ }^{51}$ de três deles. Ao fim do processo, a Junta condenou a firma a reintegrar os trabalhadores estáveis e a pagar a todos eles os direitos devidos. Insatisfeita, a reclamada recorreu ao CRT. Porém, antes que o recurso fosse apreciado, foi homologado um acordo extrajudicial celebrado entre as partes. Os reclamantes receberam alguma quantia a título de indenização e aqueles com mais de dez anos de casa renunciaram ao direito de estabilidade.

Esse tipo de resultado deu à Justiça do Trabalho a pecha de "justiça com desconto". ${ }^{52}$ No entanto, precisamos considerar que a reclamada ignorou os direitos de seus empregados, os quais só conseguiram algum resultado depois de instaurar uma ação trabalhista que pressionou a empregadora a dar-Ihes uma resposta.

Para o caso do nosso artigo, é importante destacar que as situações adversas ocasionadas pela guerra não foram recebidas com apatia ou aceitação da classe trabalhadora, afinal o argumento de escassez de matéria-prima geralmente era rebatido com o de coação, abuso ou irresponsabilidade patronal devido à falta de planejamento.

O proprietário do Armazém Real alegou que "em face da crise séria" que o comércio em geral vinha atravessando, não poderia pagar de imediato a importância a que foi condenado. E que, por isso, desejava "[...] entrar em acordo com o reclamante, no sentido de dividir o pagamento em prestações [...]"53 Em resposta, o advogado do reclamante diz que, infelizmente, não poderia aceitar a proposta, visto que seu cliente estava desempregado e que, apesar da situação do ex-patrão, este ainda possuía mais recursos que o reclamante. Sob a ameaça de citação e penhora, o reclamado efetuou pagamento integral da importância a que foi condenado. A

50 TRT3, Proc.: 01/566/1944, p. 5.

51 De acordo com a Lei 62, de 5 de junho de 1935, o empregado que atingisse 10 anos ou mais de serviços prestados ao mesmo estabelecimento adquiria estabilidade profissional e só poderia ser demitido a pedido ou por motivos devidamente comprovados de falta grave, desobediência, indisciplina ou causa de "força maior". É interessante notar que o direito à estabilidade era relativamente recente e que os empregadores tentavam utilizar qualquer brecha para escaparem dessa responsabilidade, como demonstraram os processos.

52 FRENCH, John D. Afogados em leis: a CLT e a cultura política dos trabalhadores brasileiros. São Paulo: Fundação Perseu Abramo, 2001.

53 TRT3, Proc.: 01/233/1942, p. 40. 
guerra tinha sido uma desculpa para o possível parcelamento da dívida. As palavras do advogado, por sua vez, demonstram que a solidariedade de guerra poderia ser considerada menos importante que as diferenças de classe.

Outra ocorrência que relativiza a efetividade da mobilização nacional é o fato de patrões e empregados burlarem as determinações legais, escapando assim do esperado pelo esforço de guerra. Isso foi muito comum, por exemplo, no caso do racionamento de gasolina. Olegário Mascarenhas conta em sua petição inicial que:

Com a vinda do racionamento deste combustível, o reclamado, apesar de toda a fiscalização das autoridades, conseguia burlar a severidade do racionamento, quardando [sic] gasolina aos seus amigos. O Recte ${ }^{54}$. [sic], como gerente e caixa da firma, quis proceder da mesma forma, vendendo 14 litros de gasolina para dois amigos seus. Deante [sic] deste fato, o reclamado despediuo do emprego, injustamente e sem o prévio aviso, como declara o mesmo Recte $\left[\right.$ sic]. ${ }^{55}$

Em outro processo em que o reclamante também alega ter sido demitido pela falta de gasolina, uma das testemunhas do reclamado disse que, durante o racionamento, "[...] todos arranjavam gazolina [sic] ilegalmente". 56

Guilherme de Andrade afirma que, com a crise de gasolina, a Mobiliadora Mundial obrigou seus empregados a fazerem entregas de móveis a pé. Apesar de ter entregado uma cadeira de balanço a um freguês, recusou-se a entregar uma cama completa, por entender que a tarefa não estava contida nas suas funções, e acabou demitido. O reclamante não estava disposto a manter a colaboração a qualquer custo com seu patrão durante a guerra. Sua dignidade prevaleceu sobre a "união nacional". ${ }^{57}$

Reservistas e convocados também movimentaram a Justiça do Trabalho. Em 1942, Gonçalves Quina \& Cia. compareceu à $2^{\underline{a}}$ JCJ porque um empregado recusava-se a rescindir o contrato de trabalho. Raimundo $A$. de Almeida, que era presidente do Sindicato dos Trabalhadores na Indústria de Construção de Belo Horizonte, alegava ser empregado estável por tempo de serviço. Por ter sido o resultado de primeira instância favorável à empregadora, Almeida interpôs recurso ao CRT. A reunião de segunda instância ocorreu depois de promulgada a lei de proteção aos reservistas, ${ }^{58}$ que proibia a dispensa de empregados em idade de

54 Recte. é uma abreviatura utilizada nos tribunais trabalhistas para se referir à reclamante.

55 TRT3, Proc.: 02/386/1942, p.1.

56 TRT3, Proc.: 02/126/1943, p. 2.

57 Proc.: 02/684/1942, p. 3.

58 Decreto-lei n. 5.689, de 22 de julho de 1943. Regula a dispensa de empregados na idade militar e dá outras providências. Coleção das Leis República. Disponível em: https://www2.camara.leg.br/atividade-legislativa/legislacao/republica. Acesso em: 22 jul. 2019. 
convocação militar. Informado por autoridades militares de que os reservistas mais requisitados eram aqueles de "[...] 21 anos inclusive a 30 anos exclusive [...]", ${ }^{59} 0$ CRT decide negar provimento ao recurso, já que o recorrente possuía 39 anos de idade. No entanto, Almeida não estava disposto a desertar do front por ter perdido as primeiras batalhas. O soldado da produção, potencial convocado para o serviço ativo do exército, investiu no enfrentamento nas trincheiras jurídicas e impetrou novo recurso, dessa vez, à terceira instância. A "crença simbólica nos direitos"60 parece ter despertado maior motivação no líder sindical que o chamado para a colaboração entre as classes. Ao fim do processo, conseguiu Cr\$10.000,00 por indenizações. Inicialmente a empregadora pretendia pagar-Ihe apenas $\operatorname{Cr} \$ 3.600,00$.

Os patrões apresentaram resistência ao Decreto-lei n. 5.689, de 22 de julho de 1943, por serem tolhidos no direito de dispensar seus empregados. Estes últimos, conscientes da estabilidade que adquiriram durante a guerra, procuraram a JT para garantir seus direitos. Vários reclamantes alegaram ter sido demitidos por patrões que não queriam pagar $50 \%$ do salário de um trabalhador ausente, caso fossem convocados.

José Geraldo B. A. Carneiro, procurou a $2^{\underline{a}}$ JCJ para reclamar contra a Folha de Minas, dentre outras coisas, horas extras em que vinha trabalhando devido à cobertura da guerra. $O$ jornalista fez questão de destacar que era brasileiro e reservista do exército, para só depois mencionar sua categoria profissional e o número da sua carteira de trabalho. ${ }^{61} \mathrm{~A}$ importância dada ao status de reservista demonstra o quanto as partes processuais achavam relevante levar ao conhecimento dos tribunais seus papéis no esforço de guerra.

Em uma ação repleta de apelos emocionais e patrióticos que não apresentavam relação com o objeto do dissídio, Alaor Gonçalves apresentou uma reclamação contra a Companhia Força e Luz de Minas Gerais na qual reivindicava indenização por dispensa injusta e aviso prévio. A Junta julgou improcedente a reclamação por acreditar que houve justa causa para a rescisão do contrato de trabalho. O reclamante recorreu ao CRT e nas suas razões aliou um discurso emotivo que recorria às proteções paternalistas da Justiça do Trabalho ao esforço de guerra:

59 TRT3, Proc.: 02/958/1942, p.57.

60 PAOLI, Maria Célia. Os trabalhadores urbanos na fala dos outros: tempo, espaço e classe na história operária brasileira. In.: LOPES, José Sérgio Leite. (org.). Cultura e identidade operária: aspectos da cultura da classe trabalhadora. Rio de Janeiro: Marco Zero, 1987.

61 TRT3, Proc.: 02/596/1943. 
[...] julgar procedente a ação, condenando a reclamada de acordo com a lei, é gritar bem alto ao Trabalhador do Brasil: 'Avante, trabalhador do Brasil! A sua pátria, nessa hora amarga que atravessa, pondo em suas mãos a taréfa [sic] dignificante do trabalho, confia em si e garante a sua integridade fazendo justiça [...]' ${ }^{62}$

Se a propaganda do Estado Novo empenhou-se em apresentar Getúlio Vargas como "pai dos pobres", "trabalhador número um da nação" e "protetor da família" atributos utilizados na construção de uma imagem positiva do governante que fosse capaz de despertar entre os trabalhadores respeito e devoção à figura do presidente -, do mesmo modo, os reclamantes e o seus advogados fizeram uso desse discurso nos seus argumentos. De acordo com o recurso, Martins era trabalhador, pobre e pai de família e, por isso, suas demandas deveriam ser reconhecidas e a decisão de primeira instância reformulada.

No contexto da guerra, elogios à justiça social e trabalhista, ao desempenho dos magistrados na tutela do hipossuficiente e trechos de discursos do presidente e outras autoridades pronunciados por ocasião do conflito fizeram parte das estratégias argumentativas de quem buscava uma decisão favorável.

Com o intuito de provar a honestidade e a benevolência da firma, o gerente dos Institutos Terapêuticos Reunidos Labofarma conta que:

Há alguns meses atrás, quando do torpedeamento do navio
"ARARAQUARA" em águas brasileiras, perderámos [sic] um
colaborador que nele viajava com destino a Recife, para onde
havia sido transferido para ocupar um cargo melhor. Quiz [sic],
entretanto, a providencia [sic] que sua família ainda ficasse no Rio,
onde ainda residem sua viuva [sic] e filhos. E, hoje, nossa firma,
em penhor e gratidão aos trabalhos daquele desditoso
colaborador, dá, à sua família, mensalmente, todos os
vencimentos que, em vida, percebia da nossa Organização. ${ }^{63}$

Também foi anexada ao dissídio uma notícia publicada em $A$ Gazeta, no dia 17 de outubro de 1942, sobre o fato de a empresa ter colocado as suas instalações à disposição dos cursos de Enfermagem e Socorro de Guerra. O conflito não apresentava relação alguma com o objeto debatido, que visava apenas a decidir se as gratificações recebidas pelo reclamante deveriam ou não entrar no cálculo de rescisão do contrato de trabalho. A inclusão do tema revela a importância que o nacionalismo e o patriotismo adquiriram na época e, mais que isso, a manipulação de tais representações pelas partes processuais como estratégia argumentativa na defesa de seus interesses no campo da Justiça do Trabalho.

62 TRT3, Proc.: 01/627/1942, p. 32. Trecho de um pronunciamento de Getúlio Vargas incluído no recurso.

63 TRT3, Proc.: 02/976/1942, p. 85. 
Francisco Otávio Duarte disse ter sido demitido por receio de que fosse chamado a prestar serviço à "extremecida Patria [sic]" 64 e pesasse no orçamento da firma. $\mathrm{O}$ advogado da reclamada, por sua vez, disse que

[...] o direito de defesa, no Direito brasileiro, que ainda subsiste
soberano e imaculado, é um postulado sagrado que respeitamos
genuflexos, porque o concedemos até aos covardes e vis traidores
de nossa Pátria. Se êsse [sic] direito de defesa é facultado até
aos nossos inimigos, por certo que não poderá ser sonegado
aos empregadores que são justamente os construtores de
nossa economia, onde repousa o poder de nossa soberania. ${ }^{65}$

Empregado e empregador disputaram reconhecimento do papel desempenhado na defesa da soberania nacional. A mobilização, nesse caso, longe de gerar unidade, gerou disputa.

Numa carta enviada à $1^{\underline{a}} \mathrm{JCJ}$, o marido de uma reclamante pede ajuda da justiça:

\begin{abstract}
Peço incarecidamente [sic] para $\mathrm{mi}$ [sic] atender, para isso eu cumpro com os meus Deveres, eu sou um reservista que estou prompto [sic] para ajudar a defender a nossa Patria [sic] qualquer horas, que precisar, eu quero que 0 artur [sic] paga [sic] a lavagem de roupas de um Anno [sic] - tenha a santa paciença [sic], Saudações, Jayme Barbosa de Oliveira. ${ }^{66}$
\end{abstract}

Para encerrar, fez questão de salientar: "O dono da casa Arthur Aninger, Ele [sic] é estrangeiro". ${ }^{67}$ Segundo a ótica de Oliveira, um soldado da produção brasileiro e disposto a defender a sua pátria não merecia aquele tratamento por parte de um empregador estrangeiro, situação que deveria ser reconhecida pela Junta.

A nacionalidade passou a ser assunto relevante nos embates judiciais. Franz Mortnschlag procurou a $1^{\text {a }}$ JCJ em agosto de 1939 por ter sido demitido sem justa causa e aviso prévio. Depois de várias audiências, quando o envolvimento do Brasil no conflito já era oficial, a reclamada julgou conveniente fazer distinção entre a composição étnica da firma e Mortnschlag: "A firma Benesch \& Cia. Muito menos estrangeira que o reclamante, eis que é composta por brasileiros natos e naturalizados, nunca se esqueceu dos seus devêres [sic] para com o corpo de seus auxiliares, nem deixou de cumprir as leis sociais do país". ${ }^{68}$ Apesar de o reclamante ser empregado estrangeiro regularizado, do ponto de vista social, tanto a Cia., que também possuía nome de origem alemã, quanto o trabalhador poderiam ser vistos

\footnotetext{
64 TRT3, Proc.: 02/68/1943, p. 2.

65 Ibidem, p. 8 (grifo nosso).

66 TRT3, Proc.: 01/439/1943, p. 3.

67 Ibidem.

68 TRT3, Proc.: 01/1191/1941, p. 26.
} 
naquele contexto como "estrangeiros", motivo pelo qual a empresa quis estabelecer entre eles algum tipo de discrepância neste aspecto.

Durante uma briga que resultou em sua demissão, Francisco A. dos Reis disse ao seu patrão que não gritasse "[...] 'primeiro porque não estava acostumado a ouvir gritos e segundo, porque era brasileiro e não admitia grito de um italiano'.". ${ }^{69}$ Ao que o filho do patrão respondeu: “Meu pai é italiano, mas eu sou brasileiro e ajo por ele.." ${ }^{70}$ Durante as audiências, o reclamado expôs que aquela era "[...] uma firma brasileira, composta única e exclusivamente de brasileiros, todos nascidos nesta Capital". ${ }^{71}$ Diante dessas alegações, o advogado do reclamante disse que o pedido deveria ser "[...] deferido in totum, não vindo ao caso em absoluto a questão da nacionalidade dos membros componentes da firma reclamada". ${ }^{72}$ A nacionalidade evidenciada no início do processo não deveria mais ser considerada. Ela se tornava importante ou não, de acordo com o andamento processual, à conveniência e ao interesse das partes.

Ressaltar a nacionalidade estrangeira dos empregadores foi uma prática comum entre os "soldados da produção" que buscaram as Juntas de Conciliação. Francisco G. de Lacerda, brasileiro, disse que o alemão chefe de sua seção havia causado sua demissão da Cia. Antártica Paulista. A Junta julgou improcedente a reclamação por ter sido provado que tinha "[...] o reclamante, em estado de embriaguez, provocado escândalo no estabelecimento". ${ }^{73}$

Quase dois anos depois, o brasileiro Francisco Lissa alegou à 1a JCJ que ele e sua família vinham sofrendo ameaças do alemão Guilherme Becker, dono da oficina em que trabalhava. Por falta de provas, a Junta negou provimento à reclamação e condenou o reclamante a pagar custas do processo. ${ }^{74}$

À medida que o Brasil se envolvia no conflito, alemães, italianos e japoneses passaram a ser apontados como eventuais "súditos do Eixo" e a receberem um tratamento que era degradante e oposto ao concedido aos "soldados da produção". Ao mesmo tempo, a legislação trabalhista se tornou mais adversa aos trabalhadores estrangeiros associados às nações do Eixo. A crescente xenofobia teve reflexos nas relações estabelecidas entre patrões imigrantes ou descendentes de imigrantes e

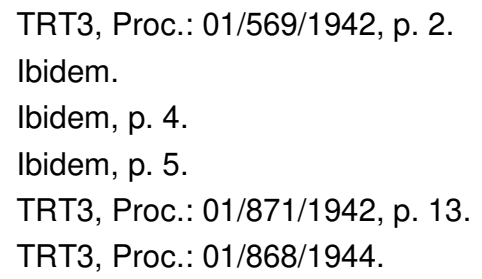


empregados nacionais e vice-versa, o que originou dissídios trabalhistas pautados pela distinção entre brasileiros e estrangeiros.

Mesmo antes de publicado o Decreto-lei n. 4.638 de 31 de agosto de 1942, que passou a facultar a rescisão do contrato de trabalho com os "súditos do Eixo", Alvico Nasckio, ${ }^{75}$ japonês, Angelo Ordrine ${ }^{76}$ e José Garcia, ${ }^{77}$ ambos italianos, e José Hainfellner ${ }^{78}$ alemão, procuraram a justiça por terem sido demitidos pela Companhia Força e Luz de Minas Gerais por motivo de suas nacionalidades "eixistas". Ao fim dos processos, todos os reclamantes, com exceção de Alvico Nasckio, receberam importâncias relativas ao tempo em que ficaram afastados, além de reintegração ao emprego. Mesmo depois de quase 16 anos de serviços prestados pelo empregado japonês, a Companhia disse que

\begin{abstract}
não quis e não pode, em sã consciência, reconsiderar a sua determinação pelos motivos óbvios [sic] seguintes: Somos todos testemunhas da maneira pela qual o Japão iniciou a guerra contra os Estados Unidos. [...] Tambem [sic] somos sabedores das atividades subrepticias [sic] que estavam e talvez ainda estejam, os japoneses desenvolvendo em nossa própria terra [...] tendo sempre em vista o plano do seu Governo, ora desmascarado, de dominar o mundo. [...] não a [sic] ninguém que, em são consciência [sic], repetimos, possa confiar num cidadão daquela nacionalidade, mesmo que, aparentemente, inofensivo. ${ }^{79}$
\end{abstract}

A instituição do referido decreto deu respaldo a uma série de demissões que já vinham acontecendo. Três dias antes de sua publicação, a firma Carneiro Santiago \& Cia. envia um comunicado ao Presidente da JCJ:

Exmo. Senhor: Pelo presente, e para os devidos fins, comunicamos a V. Excia. Que, nesta data, dispensamos dos nossos serviços na Fábrica Nacional de Aviões de Lagoa Santa, os seguintes operários extrangeiros [sic]: Klemens Sweins Alemão [sic] Ferdinand Glatz Austriaco [sic] João Sadra Alemão. Valendonos do ensejo, apresentamos a V. Excia. Os nossos protestos de especial apreço, elevada estima e alta consideração, subscrevendo-nos muito ATENCIOSAMENTE. ${ }^{80}$

No mês seguinte, Ferdinand Glatz iniciou um processo contra a empresa. Porém, como a primeira audiência aconteceu após a vigência do decreto, a reclamada teve tempo de regularizar a demissão dos empregados com bases legais, e o reclamante foi dispensado.

\footnotetext{
75 TRT3, Proc.: 01/1457/1941.

6 TRT3, Proc.: 01/1455/1941.

77 TRT3, Proc.: 02/1458/1941.

78 TRT3, Proc.: 02/80/1942.

9 TRT3, Proc.: 01/1457/1941, p. 9.

80 TRT3, Proc.: 02/710/1942, p. 3.
} 
As violências étnicas tiveram o seu ápice em agosto de 1942, quando, em virtude dos protestos contra o afundamento de navios brasileiros por submarinos alemães, vários estabelecimentos de proprietários "eixistas" foram depredados pela massa popular.

Quatro empregados da Padaria Pérola reclamaram aviso prévio, descanso remunerado, justa causa, restante de salário, horas extras e férias. O alemão Bertoldo Preisner disse que "[...] não dispensou os Rectes, pois paralizou [sic] os seus serviços com as depredações verificadas em seu estabelecimento [...]", ${ }^{1}$ que nunca desrespeitou direitos trabalhistas de seus empregados e que eram eles quem deviam importâncias relativas aos pães que levavam todos os dias para casa, além de valores que subtraíram da "féria" (receita do dia) durante as depredações. Ao longo das audiências, os reclamantes confessam terem saqueado a padaria durante os protestos e que alguns deles eram devedores de salários adiantados quando procuraram a justiça. Ao fim do caso, o reclamado foi obrigado a pagar aos reclamantes parte do que reivindicaram, podendo descontar do pagamento as quantias que lhe deviam.

Domitília Magalhães também procurou a Justiça do Trabalho após ter sido demitida pela Casa Hermanny, propriedade de alemães atacada pela massa popular. Uma das testemunhas da própria reclamante disse que "não pediu indenização à firma reclamada e nem contra esta moveu e nem moverá qualquer reclamação judicial por saber que a situação da firma é dolorosa, não devendo, por isso, ser acionada". ${ }^{82}$ Apesar de testemunhas e provas periciais atestarem a ruína da reclamada, a reclamante decidiu levar o processo adiante e não desistiu da causa até obter uma quantia razoável a título de seus direitos.

Outra trabalhadora que não abriu mão do que lhe era devido a despeito da aclamada paz social entre as classes ou da situação de falência de seu ex-patrão, foi Maria Augusta da Silva. A cozinheira, que trabalhava para Mário Aguiar em seu bar, reivindicou descanso remunerado, horas extras e salário em atraso depois que o estabelecimento de seu patrão foi destruído. No mês seguinte, o reclamado pagou à reclamante o valor integral a que foi condenado. Por não ter pagado, porém, as custas do processo, o presidente da JCJ pediu para que fosse efetuada a penhora daquele valor. No entanto, o oficial de diligências afirmou não ter encontrado nada

81 TRT3, Proc.: 02/620/1942, p. 12

82 TRT3, Proc.: 01/763/1942, p. 6. 
de valor que pudesse penhorar, já que o executado estava em "verdadeiro estado de miserabilidade". ${ }^{83}$

Os casos de depredação são exemplares dos limites da "ampliação de afinidades" ou de uma pretensa colaboração entre trabalhadores e patrões. O fato de os empregadores terem sofrido perdas ou alcançado o "estado de miserabilidade" não foi o suficiente para criar entre todos os empregados uma empatia que os fizesse desistir dos seus direitos. Por outro lado, os resultados dos processos que envolveram imigrantes ora beneficiaram brasileiros, ora estrangeiros, o que evidencia que o esforço do governo e das elites empresariais na construção de inimigos internos que fundamentassem a vigilância e a disciplina fabril necessárias à "batalha da produção" não conseguiram construir um consenso sobre o caráter dos "súditos do Eixo". Nacionalismo e xenofobia não eram apenas representações estáticas emanadas de cima, mas instrumentos de disputa por interesses diversos.

\section{Considerações Finais}

Embora existisse um projeto político do Estado e da elite empresarial para a criação de uma representação de "soldados operários" que, de uma forma mais duradoura, pudesse ajudar a construir entre os "trabalhadores do Brasil" uma cultura política afeita à disciplina e à colaboração entre as classes, a realidade vivida por estes não pôde ser completamente abarcada pelo plano.

A propaganda do Estado Novo para a mobilização nacional durante a Segunda Guerra Mundial foi confrontada com outros eventos que o conflito trouxe para o cotidiano dos trabalhadores e se somaram a situações que não se limitaram a ele. Os operários não estavam preocupados apenas com a guerra, mas também com lutas cotidianas que envolviam necessidades mais imediatas, como o próprio sustento ou o da família, a carestia, o desrespeito aos direitos trabalhistas, o desemprego e várias outras que já existiam antes do confronto. O esforço de guerra empreendido pelo Estado somou-se a uma gama de experiências já vividas por aqueles sujeitos que, submetidas a um conjunto de processos simultâneos, foram responsáveis por tornar o comportamento e os anseios dos trabalhadores algo que não pôde ser completamente presumido pelas expectativas governamentais.

Isso não significa que a propaganda para a mobilização tenha sido totalmente ineficaz. O próprio fato de o conflito e as leis criadas em sua decorrência terem sido largamente mencionados nos processos denota o alcance

83 TRT3, Proc.: 01/777/1942, p. 11. 
do empreendimento. No entanto, apontamos aqui a complexidade e os limites presentes na dinâmica desse processo.

Em desacordo com a aclamada paz entre as classes, as batalhas judiciais podem ser interpretadas como experiências genuinamente classistas. Participavam das audiências o vogal dos reclamantes e o vogal dos reclamados, também chamados de juízes classistas, que representavam, respectivamente, o interesse dos empregados e dos patrões. Em termos jurídicos adotados nos próprios tribunais, dissídio trabalhista era sinônimo de conflito trabalhista. Por mais que o Estado pudesse reivindicar um esforço no sentido da colaboração entre as classes e, na palavra dos magistrados, a "natureza" da Justiça do Trabalho fosse a conciliação, em suas estruturas e práticas ela era paritária.

O exercício dos trabalhadores em lidar com as restrições impostas pelo Estado Novo e o discurso governamental construído em torno da importância do trabalhador e da Justiça do Trabalho (veiculado de forma intensiva a partir da entrada do Brasil na guerra) alteraram a cultura política dos trabalhadores, mas no sentido do enfraquecimento do próprio regime. A ambiguidade de lutar em nome da democracia contra os regimes totalitários nazifascistas foi uma das causas da queda da ditadura do Estado Novo, mas as consequências políticas da participação do Brasil na guerra somaram-se às transformações que passaram a reger as relações de trabalho no país, que incluíram a ampliação da noção da responsabilidade do Estado na garantia de direitos sociais e trabalhistas e das instituições estatais como canais de luta por direitos.

Recebido em 15/08/2019

Aprovado em 05/10/2019 